\title{
Autism and Emotion: A Narrative Review
}

\author{
Sagayaraj Kanagaraj $^{10}$ S. Devishrree ${ }^{2} \quad$ J. Swetha ${ }^{3}$ \\ $\begin{array}{lll}\text { Jincy Cherian }^{6} & \text { C.N. Ram Gopal } & \text { S. Karthikeyan } \\ & \end{array}$ \\ ${ }^{1}$ Department of Counseling Psychology, Faculty of Allied Health Sciences, \\ Chettinad Hospital and Research Institute, Chettinad Academy of \\ Research and Education, Kelambakkam, Chennai, Tamil Nadu, India \\ 2 Department of Clinical Psychology, National Institute for \\ Empowerment of Persons with Multiple Disabilities (Divyangjan), \\ East Coast Road, Chennai, Tamil Nadu, India \\ 3 Department of Rehabilitation Psychology, National Institute for \\ Empowerment of Persons with Intellectual Disabilities (Divyangjan), \\ Manovikas Nagar, Secunderabad, Telangana, India \\ ${ }^{4}$ Department of Counseling Psychology, University of Madras, \\ Chennai, Tamil Nadu, India \\ ${ }^{5}$ School of Biosciences and Technology, Vellore Institute of \\ Technology, Vellore, Tamil Nadu, India \\ ${ }^{6}$ Department of Psychology, Dayalbagh Educational Institute, Agra, \\ Uttar Pradesh, India \\ J Health Allied Sci ${ }^{\mathrm{NU}}$ 2022;12:196-207.
}

\begin{abstract}
Keywords

- autism

- emotion

- theories of emotion

- theory of mind

Autism spectrum disorder (ASD) includes a variety of childhood-onset and lifelong neurodevelopmental condition with an enduring impact on multiple domains of functioning characterized by persistent deficits in social communication, restricted and repetitive behavior interest, and activities. They often find it hard to recognize and control emotions but their emotional expression can be improved by various intervention techniques that in turn can help them understand and respond more appropriately to other people. Problems in the area on emotional reciprocity among individual with ASD involve recognizing, understanding, expressing, and regulating emotions. Their ability in emotional reciprocity is often improved with a comprehensive treatment approach, especially by focused emotional enhancement intervention. In this review, we followed the standard IMRAD (Introduction, Methods, Results, and Discussion) structure to critically examine the condition of autism and its relation with genetic mechanism, and how theories of emotion and theory of mind associated with persons with ASD, some of the widely used assessment tools and future research direction in the emotional development of individuals diagnosed with ASD by using the narrative review method. Records collected through research databases such as Scopus, PubMed, Web of Science, Medline, EBSCO and published books with ISBN (International Standard Book Number), and published test manuals were evaluated in-depth and summarized based on the subtopic of the proposed title. A critical theoretical analysis of the genetic mechanism of emotions, theories of emotions, and theory of mind was explained in connection with ASD.
\end{abstract}

\section{B. Krishna Priya ${ }^{4}$ Srivarshini Sankar ${ }^{5}$}

Address for correspondence Sagayaraj Kanagaraj, MSc, Department of Counseling Psychology, Faculty of Allied Health Sciences, Chettinad Hospital and Research Institute, Chettinad Academy of Research and Education, Kelambakkam, Chennai 603103, Tamil Nadu, India (e-mail: harrysagayaraj@gmail.com).
DOI https://doi.org/ $10.1055 / \mathrm{s}-0041-1736277$
ISSN 2582-4287.

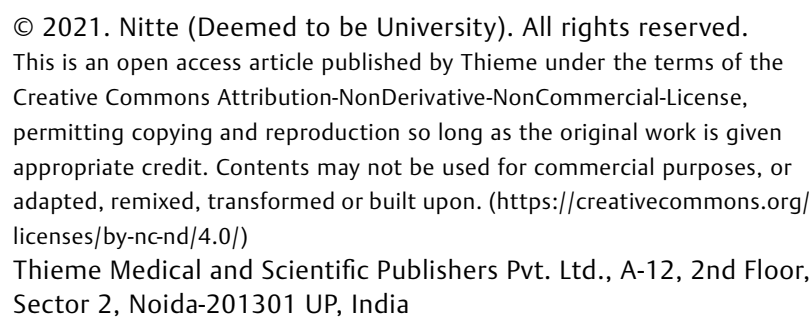

(c) 2021. Nitte (Deemed to be University). All rights reserved. This is an open access article published by Thieme under the terms of the Creative Commons Attribution-NonDerivative-NonCommercial-License, permitting copying and reproduction so long as the original work is given appropriate credit. Contents may not be used for commercial purposes, or adapted, remixed, transformed or built upon. (https://creativecommons.org/ licenses/by-nc-nd/4.0/) Thieme Medical and Scientific Publishers Pvt. Ltd., A-12, 2nd Floor, Sector 2, Noida-201301 UP, India 


\section{Introduction}

International Classification of Diseases, 11th revision (ICD-11), which was developed and released by the World Health Organization (WHO) in 2018, had given an updated criteria for autism spectrum disorder (ASD). ${ }^{1}$ As per the updated guidelines of ICD-11, ASD is characterized as the continues deficiencies in the ability to initiate and continue the social interaction and communication with a range of restricted, repetitive pattern of behavior. The onset of this disorder occurs in early childhood and tends to continue throughout the person's life. It severely causes significant impairment in one's personal, family, and social life and becomes increasingly common in many parts of the world. The rise in diagnosis of autism impacts us all, seeking greater understanding and awareness of these complexities and comorbid condition. ${ }^{2}$ Emotional and behavioral difficulties are the serious set of associated issues for an individual with ASD and theses problems place a high burden on their family caregivers and clinical service providers. There had been numerous studies on the prevalence of autism, ${ }^{3-5}$ comorbid condition of ASD, ${ }^{6-8}$ effective interventions and treatments of ASD, ${ }^{9-13}$ and clinical drug trial $^{14-17}$ that were conducted, and still, several studies have been performed to produce the vast knowledge on research in ASD. However, the emotional reciprocity of individual with ASD is yet to be explored in the medical and psychological field, for which this narrative review may shed a scientific spotlight.

As per WHO $(2021)^{18}$ report, $\sim 1$ in 160 children has condition of autism spectrum worldwide. From the report of Sun and Allison, ${ }^{19}$ it was estimated that 14.8 in 10,000 were diagnosed with ASD in the Asia. Hossain et al, ${ }^{20}$ in the identification of prevalence rate of ASD in South Asian countries like Bangladesh, India, Pakistan, Nepal, Sri Lanka, Bhutan, Maldives, Afghanistan, reported that 1 in 93 children were diagnosed with ASD. The first rigorous study of autism estimation in India by Arora et $\mathrm{al}^{21}$ found that $\sim 1$ in 100 children under the age of 10 has ASD and nearly 1 in 8 has at least one neurodevelopmental-related condition. Moreover, the incidence of autism is not increasing; the prevalence is increasing due to higher rate of diagnosis.

\section{Materials and Methods}

The articles for this review were collected from the published records of research databases such as Scopus, PubMed, Web of Science, Medline, EBSCO, published books with ISBN and standard test manuals. The records were collected from 1870 to 2020 and screened based on the following inclusion and exclusion criteria.

Inclusion criteria as follows:

1. Language of publication must be in English.

2. Original research and review articles, randomized control trial, and experimental studies.

3. Published books with ISBN and standard test manuals.

4. Peer-reviewed articles indexed in Scopus, PubMed, Web of Science, Medline, EBSCO databases.

5. Already been cited for scholarly reference.
Exclusion criteria as follows:

1. Non-English literatures.

2. Gray literatures.

3. Any Web site sources.

4. Nonpeer-reviewed sources such as newspaper, magazine articles.

5. Articles which are not previously cited for scholarly reference.

\section{Screening and Selection}

Approximately 50,000 articles were published in connection with autism between the period of 1870 and 2020. Based on the topic relevant, over 110 articles were selected carefully considering the inclusion criteria and critically examined as per the subtopic of the proposed review (-Fig. 1). Brief summary of the selected articles which are included in this study are given in - Table $\mathbf{1}$.

\section{Results}

\section{Autism and Its Associated Genetic Mechanisms in Relation with Emotion}

ASD is a high genetic heterogeneous and possibly caused by the gene variations. Autistic features can occur as part of some genetic condition and it is estimated that $20 \%$ of the children with ASD will have a diagnosable genetic influence. $^{22}$ Genetic defects involving the formation of synapses

Flow chart of screening of the articles

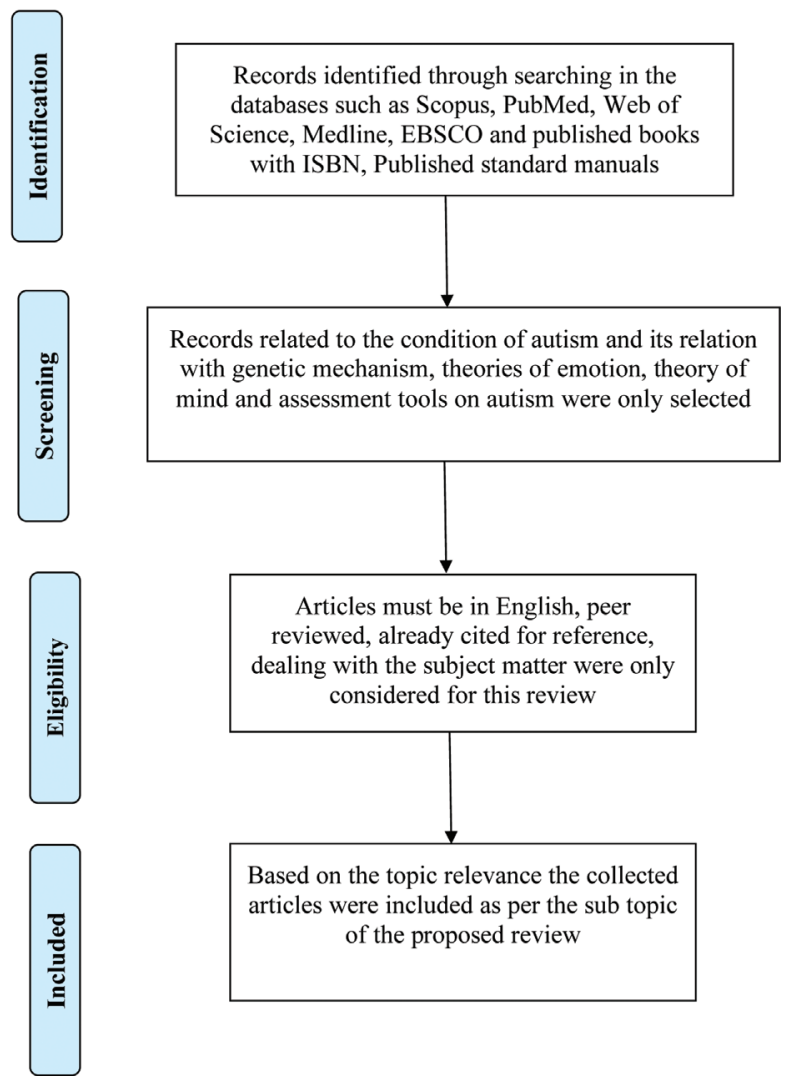

Fig. 1 Flowchart of screening of the articles 
Table 1 Summary of the included article (In the order of subtopics)

\begin{tabular}{|c|c|c|}
\hline Author(s) and Year & $\begin{array}{l}\text { Research area/study } \\
\text { measures }\end{array}$ & Brief summary \\
\hline \multicolumn{3}{|c|}{ Autism and its associated genetic mechanisms in relation with emotion } \\
\hline $\begin{array}{l}\text { Scanlon et al }(1979)^{26} \\
\text { Enoch et al }(2003)^{27} \\
\text { Meyer-Lindenberg and Weinberger }(2006)^{31} \\
\text { Dapretto et al }(2006)^{28} \\
\text { Yavich et al }(2007)^{25} \\
\text { Rzhetsky et al }(2007)^{32} \\
\text { Pessoa (2010) } \\
\text { Ursini et al }(2011)^{30}\end{array}$ & $\begin{array}{l}\text { COMT } \\
\text { Catechol-O-methyltransferase }\end{array}$ & $\begin{array}{l}\text { COMT is an enzyme that is involved in the } \\
\text { degradation of the neurotransmitters (e.g., } \\
\text { dopamine, epinephrine, and norepinephrine) } \\
\text { and association of COMT Val158Met } \\
\text { polymorphism might have genetic } \\
\text { association with autism }\end{array}$ \\
\hline $\begin{array}{l}\text { Piven et al }(1991)^{34} \\
\text { Lesch et al }(1996)^{33} \\
\text { Tordjman et al }(1997)^{35} \\
\text { Hariri et al }(2002)^{37} \\
\text { Caspi et al }(2003)^{40} \\
\text { Heinz et al }(2005)^{38} \\
\text { Pezawas et al }(2005)^{39} \\
\text { Hu et al }(2006)^{36} \\
\text { Lonsdorf et al }(2009)^{41}\end{array}$ & $\begin{array}{l}\text { SLC64A } \\
\text { Serotonin transporter }\end{array}$ & $\begin{array}{l}\text { SLC6A4 is a significant autism candidate } \\
\text { gene. The SLC6A4 mutation (HTT promoter } \\
\text { polymorphism) has been linked to anxiety in } \\
\text { the general population, and this, along with } \\
\text { evidence of increased autism stress } \\
\text { sensitivity and a higher incidence of anxiety } \\
\text { disorder in autistic groups, has enhanced HTT } \\
\text { concern in autism }\end{array}$ \\
\hline $\begin{array}{l}\text { Windle et al (1997) } \\
\text { Kirsch et al }(2005)^{45} \\
\text { Lee et al }(2009)^{42} \\
\text { Yamasue }(2013)^{51} \\
\text { Kirsch }(2015)^{43} \\
\text { Auyeung et al }(2015)^{47} \\
\text { LoParo and Waldman }(2015)^{50} \\
\text { Koch et al. }(2016)^{46} \\
\text { Yamasue and Domes }(2018)^{49} \\
\text { Lucht et al }(2019)^{48}\end{array}$ & $\begin{array}{l}\text { OXTR } \\
\text { Oxytocin receptor }\end{array}$ & $\begin{array}{l}\text { Oxytocin is a primary transmitter of nervous } \\
\text { behavior, especially in social situations, since } \\
\text { it regulates the release of corticotrophin- } \\
\text { releasing hormone. Single nucleotide } \\
\text { polymorphisms (SNPs) in the OXTR gene have } \\
\text { been linked to a lack of interest in } \\
\text { relationships, infidelity, and social } \\
\text { engagement. Autism spectrum disorder } \\
\text { (ASD) symptoms have been associated to } \\
\text { oxytocin receptor gene genotypes in several } \\
\text { studies }\end{array}$ \\
\hline $\begin{array}{l}\text { Ahima and Harlan }(1990)^{52} \\
\text { Kovács et al }(2000)^{53} \\
\text { Binder et al }(2004)^{55} \\
\text { Ising et al }(2008)^{53} \\
\text { Willour et al }(2009)^{56} \\
\text { Bevilacqua and Goldman }(2011)^{24} \\
\text { Criado-Marrero et al }(2018)^{54}\end{array}$ & $\begin{array}{l}\text { FKBP51 } \\
\text { Glucocorticoid receptor- } \\
\text { regulating co-chaperone of } \\
\text { stress proteins }\end{array}$ & $\begin{array}{l}\text { Hsp90, FKBP51, or FKBP52, as well as Hsp70 } \\
\text { and p23 heterocomplexes, bind to } \\
\text { glucocorticoid receptor (GR). Functional } \\
\text { mutations in the FKBP5 gene have been } \\
\text { associated with antidepressant responses, } \\
\text { recurrence of mood disorders, attempted } \\
\text { suicides in bipolar patients, and questionable } \\
\text { regularization of stress-induced cortisol } \\
\text { production. Due to its wide spectrum of } \\
\text { amplification, FKBP51 has been related to } \\
\text { several medical conditions, including ASD }\end{array}$ \\
\hline $\begin{array}{l}\text { Davis }(1992)^{67} \\
\text { Harmar and Lutz }(1994)^{61} \\
\text { Hashimoto et al }(2006)^{62} \\
\text { Falluel-Morel et al }(2008)^{59} \\
\text { Ghzili et al }(2008)^{60} \\
\text { Mounien et al }(2009)^{63} \\
\text { Ressler et al }(2011)^{58} \\
\text { Stroth et al }(2011)^{64} \\
\text { Dias and Ressler et al }(2013)^{65} \\
\text { Giustino and Maren et al }(2015)^{69} \\
\text { Mercer et al }(2016)^{66} \\
\text { Diener et al }(2016)^{68}\end{array}$ & PACAP & $\begin{array}{l}\text { The PAC1R binding of PACAP controls a } \\
\text { variety of biological activities. Following fear } \\
\text { training, rats showed increased expression of } \\
\text { PAC1R in the amygdala, showing that it is } \\
\text { important for emotional regulation. PAC1R } \\
\text { may serve as a genetic modifier in ASD and } \\
\text { provide a novel biomarker for stratifying } \\
\text { individuals with ASD if it is validated in larger } \\
\text { cohorts }\end{array}$ \\
\hline \multicolumn{3}{|l|}{ Theories of emotion and theory of mind } \\
\hline $\begin{array}{l}\text { James }(1884)^{76} \\
\text { Lange }(1912)^{77} \\
\text { Gaigg }(2012)^{74} \\
\text { Clarke }(2015)^{78} \\
\text { Fitzpatrick et al }(2018)^{75}\end{array}$ & James-Lange theory & $\begin{array}{l}\text { This theory proposes that emotion occurs as a } \\
\text { result of physiological reaction to certain } \\
\text { events or stimuli. This theory is more suitable } \\
\text { for neurotypical individual who perceives } \\
\text { those events or stimuli appropriately and may } \\
\text { not be connected to individual with } \\
\text { neurodevelopmental disorders such as ASD }\end{array}$ \\
\hline
\end{tabular}


Table 1 (Continued)

\begin{tabular}{|c|c|c|}
\hline Author(s) and Year & $\begin{array}{l}\text { Research area/study } \\
\text { measures }\end{array}$ & Brief summary \\
\hline $\begin{array}{l}\text { Newman et al }(1930)^{82} \\
\text { Sifneos }(1973)^{84} \\
\text { Poquérusse et al }(2018)^{83} \\
\text { Gu et al }(2018)^{79} \\
\text { Vaughan et al }(2020)^{80} \\
\text { Friedman }(2010)^{81}\end{array}$ & Cannon-Bard theory & $\begin{array}{l}\text { This theory proposes that external events or } \\
\text { stimuli induce bodily reaction and emotion } \\
\text { simultaneously. From the reviews, it can be } \\
\text { inferred that it is not evident that bodily reaction } \\
\text { and feelings can raise simultaneously in the } \\
\text { individual with ASD }\end{array}$ \\
\hline $\begin{array}{l}\text { Schachter and Singer }(1962)^{87} \\
\text { Hadjikhani et al }(2014)^{85} \\
\text { Meng et al }(2017)^{86}\end{array}$ & Schachter-Singer theory & $\begin{array}{l}\text { This theory proposes that external event or } \\
\text { stimuli bring about physical arousal and } \\
\text { cognitive reasoning by which we exhibit } \\
\text { emotions. But due to the } \\
\text { neurodevelopmental condition, it could not } \\
\text { be related to individual having the condition of } \\
\text { ASD }\end{array}$ \\
\hline $\begin{array}{l}\text { Tager-Flusberg }(1999)^{88} \\
\text { Macari et al }(2018)^{89}\end{array}$ & Cognitive appraisal theory & $\begin{array}{l}\text { It is the subjective cognitive interpretation } \\
\text { made by an individual to stimuli in the } \\
\text { environment but autism itself is universally } \\
\text { associated with cognitive impairment; hence, } \\
\text { this theory may not applicable for individuals } \\
\text { with the condition of ASD }\end{array}$ \\
\hline $\begin{array}{l}\text { Lazarus }(1991)^{90} \\
\text { Green et al }(1995)^{91} \\
\text { Barrett et al }(2007)^{92}\end{array}$ & Facial feedback hypothesis & $\begin{array}{l}\text { It emphasizes that individual's facial } \\
\text { expressions are connected to experiencing } \\
\text { emotions but most individuals with ASD } \\
\text { exhibit blend facial expression and have the } \\
\text { condition of alexithymia; hence, it may not } \\
\text { bring about theoretical connection in autism }\end{array}$ \\
\hline $\begin{array}{l}\text { Darwin }(1872)^{93} \\
\text { Premack Woodruff }(1978)^{95} \\
\text { Baron-Cohen et al }(1985)^{97} \\
\text { Baron-Cohen }(1991)^{96} \\
\text { Perkins et al }(2010)^{94}\end{array}$ & Theory of mind & $\begin{array}{l}\text { It is an understanding of emotion and social } \\
\text { cognitive skills on one self and of others. This } \\
\text { functional theory of mind is closely } \\
\text { associated in people with ASD but even } \\
\text { among the individual with autism, the } \\
\text { variation in functioning found based on their } \\
\text { severity level }\end{array}$ \\
\hline \multicolumn{3}{|l|}{ Assessments in autism } \\
\hline 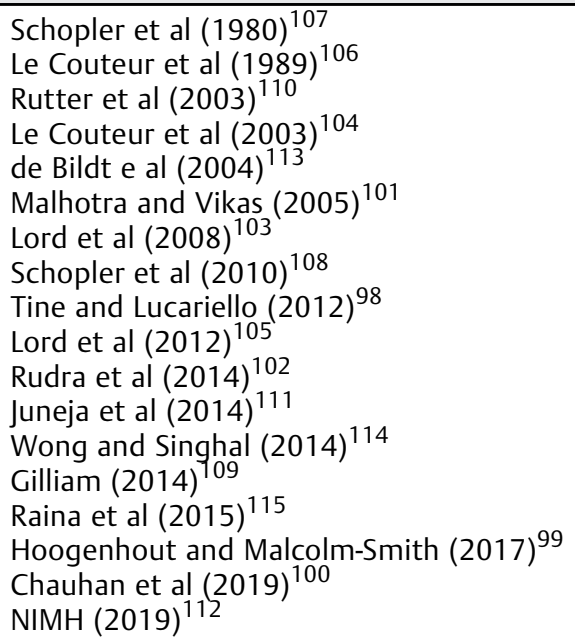 & $\begin{array}{l}\text { The Autism Diagnostic } \\
\text { Observation Schedule (ADOS) } \\
\text { Autism Diagnostic } \\
\text { Observation Schedule, } 2^{\text {nd }} \\
\text { edition (ADOS-2) } \\
\text { The Autism Diagnostic } \\
\text { Interview-Revised (ADI-R) } \\
\text { Childhood Autism Rating Scale } \\
\text { (CARS-2) } \\
\text { The Gilliam Autism Rating } \\
\text { Scale (GARS-3) } \\
\text { The Social Communication } \\
\text { Questionnaire (SCQ) } \\
\text { INCLEN Diagnostic Tool for } \\
\text { Autism Spectrum Disorder } \\
\text { (INDT-ASD) } \\
\text { Indian Scale for Assessment of } \\
\text { Autism (ISAA) }\end{array}$ & $\begin{array}{l}\text { These are the few widely used assessment } \\
\text { tools on autism that comprehensively } \\
\text { measure the cognitive, behavior, social } \\
\text { communication, speech and language } \\
\text { communication, and emotional reciprocity } \\
\text { and considered as gold standard }\end{array}$ \\
\hline
\end{tabular}

and branching of neurites result in a wide range of neuropsychiatric disorders including ASD. ${ }^{23}$ Identifying the genetic mechanisms, which control emotion processing, can help to define the mechanisms with vulnerability to emotional problems in ASD. The five genes that are related or associated with emotions are COMT (catechol-O-methyltransferase), SLC6A4 (serotonin transporter), OXTR (oxytocin receptor gene), FKBP5 (glucocorticoid receptor-regulating co-chaperone of stress proteins), and PACAP (pituitary adenylate cyclase-activating polypeptide). ${ }^{24}$

\section{COMT}

COMT plays a major part in brain dopamine and norepinephrine catabolism. COMT enzyme has a significant function in 
the prefrontal cortex where dopamine transporter is not abounding. ${ }^{25}$ Val158Met is a common functional mutation that changes enzyme stability and is expected to decrease the dopamine levels in the prefrontal cortex. ${ }^{26}$ Although associated with better cognitive performance, the Met158 allele results in higher anxiety and emotionality. ${ }^{27}$ Met158 contributes to greater emotionality when it was examined by positron emission tomography and functional magnetic resonance imaging (fMRI). COMT Met/Met individuals exhibit improved reactivity and greater integration of the brain circuitry involved in generation and control of emotional responses. ${ }^{28}$ The circuitry involves the prefrontal cortex and hippocampus, amygdala, orbitofrontal, and ventrolateral cortex. It is obvious that specific regions of the brain play a crucial role in emotion. ${ }^{29}$ It is also suggested that, at the CpG dinucleotide produced by the Val158 allele, greater stress correlates with decreased methylation, likely modifying the expression of COMT and its associated traits. ${ }^{30}$ We are unaware of the research associating Val158Met polymorphism with autism, although there is significant evidence of schizophrenia, and analysis of comorbidity suggests a genetic association with autism, schizophrenia, and bipolar disorder. ${ }^{31,32}$

\section{SLC64A}

It is primarily associated with anxiety, aggression, and attention. The efficacy of selective serotonin reuptake inhibitors, SLC6A4, is a strong autism candidate gene, and is a primary target in the therapeutic intervention of the anxiety and depression. 5-HTTLPR (serotonin-transporterlinked promoter region) is a specific polymorphism, located upstream of the SLC6A4 gene. ${ }^{33}$ SLC6A4 variants were reported to be influencing the chronic autistic behavior. In addition, the documented correlation of an HTT promoter polymorphism with anxiety in the normal population combined with evidence of higher autism stress sensitivity and an elevated prevalence of anxiety disorder in the autism communities of individuals further intensified HTT concern in autism. ${ }^{34,35}$ Compared with the 16 repeat allele (L), a 14-repeat allele $(S)$ has reduced transcriptional efficiency. In addition, the $L$ allele often contains an $A \rightarrow G$ substitution, which makes it fundamentally comparable to the lowexpression $S$ allele by linking a defined transcription factor. $^{36}$ Studies suggested that the low transcription allele (S) enhanced amygdala activation after consciously viewing the emotional stimuli. Accordingly, connectivity experiments showed that the low-expression allele impaired the functional connection between the amygdala and the ventromedial prefrontal cortex and the pregenual cingulate, potentially impairing the prefrontal medial cortex's induction of fear. ${ }^{37-39}$ It was mentioned that lowtranscription allele carriers appear more likely on being depressed and suicidal along with stressful experiences compared with the general population with two copies of the allele with high expression. The mechanism of effects of the reduction of 5-HTT functional genotypes on emotions includes enhanced development of conditioned responses to fear. ${ }^{40,41}$

\section{OXTR}

Oxytocin is identified in very obvious forms, in all vertebrates and most invertebrates; it plays a significant function in the regulation of maternal activity and is among the few. ${ }^{42,43}$ Oxytocin regulates the hypothalamic release of corticotrophin-releasing hormone ( $\mathrm{CRH})$ that is engaged in the regulation of amygdalin stress response. ${ }^{44,45}$ It thus serves as the primary transmitter of anxious behavior, particularly under social circumstances. ${ }^{46}$ At the genetic level, single nucleotide polymorphisms in the OXTR are linked with a lack of enthusiasm for relationships, adulterous relationship, and a general deficit in social contact. ${ }^{47,48}$ The nonverbal communication of facial expression, eye gaze, and gesture is found to be deficits in the social-emotional communication in ASD due to oxytocin effect; also several studies have employed that symptoms of ASD are associated with genotypes in OXTR. ${ }^{49-51}$

\section{FKBP5}

Acute stress induces the hypothalamic release of the $\mathrm{CRH}$ from the paraventricular nucleus to the pituitary, where it activates the adrenocorticotropic hormone (ACTH) secretion. CRH specifically, and by the action of ACTH, controls the release of adrenal cortisol, steroidogenesis, and catecholamine synthesis through the adrenal gland. ${ }^{24}$ Cortisol, the stress hormone, targets two main receptors: a receptor of mineralocorticoids and a glucocorticoid receptor (GR). GR is particularly highly expressed in main regions of the hypothalamic-pituitary-adrenal (HPA) axis namely hippocampus, hypothalamus and amygdala. ${ }^{52}$ Negative feedback to block CRH release is necessary for normal functioning of the HPA axis, prohibiting persistent or excessive activation. ${ }^{53}$ The response to stress with HPA is necessary for survival and helps to trigger a fight-or-flight response. Intracellularly, GR binds to a complex of multimeric chaperones. Intracellularly, GR binds to a complex of multimeric chaperones. Such heterocomplexes consist of Hsp90, FKBP51 or FKBP52, and Hsp70 and p23. ${ }^{54}$ Functional mutation of the FKBP5 gene was associated with an antidepressant response, relapse of mood disorder, ${ }^{55}$ attempted suicides in bipolar patients, ${ }^{56}$ and inconclusive regularization of stress-induced cortisol secretion. Due to the plethora of functions and means of regulation of FKBP51 is associated with several medical conditions that include ASD. ${ }^{57}$

\section{PACAP}

The PACAP and its selective PAC1 receptor have recently been shown to play a role in abnormal stress response underlying posttraumatic stress disorder (PTSD) in females. ${ }^{58}$ PACAP regulates several biological processes by PAC1R binding, including neural development, cell stress response, glucose metabolism and feeding, neuroendocrine secretion enhancement in pituitary cells, and circadian clock regulation, and it was also found that Pac1r seems to play a key role in emotional regulation, as rodents showed enhanced expression of Pac1 $r$ in the amygdala after fear conditioning. ${ }^{59-64}$ At the functional level, the estrogen response element (ERE) sequence of the CC risk genotype compromises ER $\alpha$ binding, 
inhibiting PAC1R transcription activation and resulting in decreased gene expression. ${ }^{65}$ Since amygdala dysfunction is a signature characteristic of PTSD, ${ }^{66-68}$ findings indicate that decreased expression of PAC1R is related to a phenotype that results from impaired amygdala function. PAC1R may serve as a genetic modifier in ASD and may provide a novel biomarker for stratifying individuals with ASD if confirmed in larger cohorts. ${ }^{69}$

From the literature, it had been identified that COMT, SLC6A4, OXTR, FKBP5, and PACAP genes directly or indirectly influence the autistic features of individuals and also any abnormalities in these functioning mechanisms cause the severe social-emotional impairments.

\section{Autism and Theories of Emotions}

There are several scientific studies that contributed to the autism research reveal the relationship between theories of emotion and emotional reciprocity state of the individual with ASD. ${ }^{70-73}$ In this category, we critically analyzed the famous theories such as James-Lange theory, Cannon-Bard theory, Schachter-Singer theory, cognitive appraisal theory, and facial feedback hypothesis and how it is not connected to the emotional regulation of individual with ASD.

\section{James-Lange Theory}

In 1884, William James first proposed that emotions have distinct bodily expression ${ }^{74}$ and later it was independently developed by Carl Georg Lange in the year 1912 on the broad topic as "The Mechanism of the Emotions." 75 In the modern psychology, the combination of these two theories is popularly known as James-Lange theory. According to this theory, emotions occur as a result of physiological reactions to a particular situation that means when an individual feels an external stimulus that results in physiological arousal. The emotional reaction followed by the physiological arousal is dependent on how the individual interprets those physiological reactions. The abnormal pain tolerance and high sensitivity to pain were noted in clinical observations on the individual with ASD, ${ }^{76,77}$ which is not usually seen in neurotypical individuals. ${ }^{78}$ However, not all individuals with ASD have a higher threshold to sensory pain and so hypothetically it can be inferred that James-Lange theory might not be closely connected with emotional reciprocity of individuals with ASD.

\section{Cannon-Bard Theory}

Walter Bradford Cannon was a physiologist and best known for his work on homeostasis and Philp Bard was the student of Cannon and their work on emotion in the early 19th century is widely called as Cannon-Bard theory. ${ }^{79}$ A disagreement of the James-Lange theory led to the development of the Cannon-Bard theory of emotion. According to Cannon-Bard, the thalamus plays a central role in emotion and it responds to an emotion-producing stimulus by sending impulses simultaneously to the cerebral cortex and other parts of the body and the emotions experienced are the result of simultaneous arousal of the cortex and the sympathetic nervous system. The theorists suggested that feeling and physiological responses are two independent components of emotion. The emotional stimulus is processed in the brain region and then it independently creates both bodily reaction and feelings that were highly criticized in that era. ${ }^{80}$ This theory cannot be associated with the individual with ASD because most individuals with ASD suffer from the condition called alexithymia. ${ }^{81}$ Alexithymia is a state of inability to identify and explain the emotional experience of one's self or others. ${ }^{82}$ As per Diagnostic and Statistical Manual of Mental Disorders, 5th edition [DSM-V] by American Psychiatric Association), one of the major diagnostic criteria for ASD is deficits in social-emotional reciprocity.

The first study on real facial expression of pain to analyze the neural correlates of the autonomic empathic process in normal individuals with individual diagnosed with ASD shows no significant differences in brain activation during the perception of pain experienced by participants of both the groups, but they found individual with ASD represented empathy to overcome the personal overarousal and distress that lead to the inappropriate empathetic behavior. ${ }^{83}$ The neurotypical individual may show appropriate bodily reaction and feelings as the result of emotion, but not all individual with ASD can express the same. Even the study by Meng et al demonstrate low autism spectrum quotient (AQ) individual responds more accurate in understanding others painful emotions when compared with high AQ individuals. ${ }^{84}$ So, the hypothetical understanding would be that all individuals are capable of perceiving external stimulus irrespective of their neurological condition; it is not evident that bodily reaction and feelings can raise simultaneously in the individual with ASD.

\section{Schachter-Singer Theory}

A theory proposed by Schachter and Singer in the year 1962 explains that emotions were thought to result from the combination of two factors or components that involves the state of general physiological arousal and a cognitive explanation for that particular arousal which leads to the subjective experience of the emotion; hence, it has been addressed as two-factor theory. ${ }^{85}$ Due to the neurological condition, most individuals with autism have difficulties in cognitive and social communication that interfere in their cognitive interpretation. ${ }^{86}$ They may not only indicate a proper emotional response to the particular stimuli but also muted response to a threat. ${ }^{87}$ Neurotypical individual cognitive interpretation to physiological arousal would be high and noncomparable to the individual with a neurologically atypical condition such as ASD.

\section{Cognitive Appraisal Theory}

According to cognitive appraisal theory of emotion, the cognitive appraisal mediates between the stimulus and the emotional response and it is often immediate and unconscious. ${ }^{88}$ The sequence of events involves the stimulus followed by the thought that results in the simultaneous experience of physiological arousal and emotion. In contrast to the two-factor theory emotion, Lazarus argued that appraisal precedes cognitive labeling, simultaneously 
stimulating both the physiological arousal and the emotional experience itself. But the condition of autism itself universally associated with cognitive impairment of varying degrees. ${ }^{89}$ Hence, similar to the above theories of emotion, cognitive appraisal theory might not be closely connected with non-neurotypical individuals.

\section{Facial Feedback Hypothesis}

The facial feedback hypothesis states that an individual's facial expressions are connected to experiencing emotions. The idea that awareness of bodily experiences is the basis of emotion. ${ }^{90}$ On the other hand, Darwin in 1872 investigated the way in which animals use facial expression and suggested facial feedback hypothesis in which he wrote that expression of an emotion intensifies it and suppression softens the emotion. ${ }^{91}$ If a person knows that the facial expressions are the ones, he or she associates with being sad, the person experiences the feeling of sadness. The contraction of facial muscle communicates what a person is feeling to oneself and others. A study was conducted to examine the mirror neuron abnormalities in children with autism, in which high functioning children with autism and matched control group underwent a fMRI while imitating and observing the emotional expression of others. Both the group performed the task equally well. However, children with autism showed no activity of the mirror neuron in the inferior frontal gyrus (pars opercularis). The dysfunction of the mirror neuron in children with autism may cause the social deficits such as deficits in imitation, theory of mind, and social communication and it is evident that autism individual finds it hard to understand the facial expression. ${ }^{92}$

\section{Theory of Mind and Autism}

The term "Theory of mind" was first coined by an US psychologist, David Premack, in one of his articles as the ability to attribute mental states, opinion, desire, emotions, and knowledge from oneself to others. Theory of mind is necessary to understand that others have beliefs, desires, intentions, and perspectives that are different from one's own. ${ }^{93}$ Premack conducted an experiment to check the presence of theory of mind in the chimpanzee. The results of the experiment suggested that the chimpanzee was able to understand the intentions, desires and emotions of the person shown in the videotapes. The theory of mind holds an assumption that each person has a mind of their own and each human can experience the presence of their own mind through reflection and introspection of one's own thoughts and behaviors. An individual does not have direct access to understand the mind of another person. However, it is possible to understand how another person's mind works through behavioral observation. Each individual's mind is unique and it is shaped by their environment, personal experience, and interactions with other humans. Understanding the intentions of another person is a determinant for understanding the mind of another person because intention represents an individual's mental states and personal events. ${ }^{94}$ A study conducted by Baron-Cohen et al, where they believed that children with autism have deficit in their "theory of mind" capacity due to which they are unable to represent their beliefs to others and predict other persons behavior. ${ }^{95}$ Deficit in the theory of mind can also have difficulties in understanding other persons perspective and difficult time with social reciprocity. A study conducted by Tine and Lucariello to differentiate the theory of mind among children with autism and Asperger's syndrome. A battery of interpersonal theory of mind and social theory of mind was administered to 39 children with autism and 34 children with Asperger's syndrome. The results of this study indicated that for both groups of children, the theory of mind differentiated and interpersonal theory of mind was stronger than the social theory of mind. However, children with autism score lower on measures of the social theory of mind in comparison to Asperger's syndrome. ${ }^{96}$

Hoogenhout and Malcolm-Smith in 2017 examined the severity level in autism by assessing the theory of mind capacity that predicted the type of school children with ASD attended. Using the hierarchical cluster analysis, the theory of mind capacity was grouped into three clusters:

1. Early developing theory of mind, which includes the ability to understand pretend play, desires, and perception knowledge.

2. False belief reasoning, which includes the ability to understand false belief reasoning, deceptive hiding, explanation of action along with cluster 1 abilities.

3. Sophisticated theory of mind understanding, which includes the ability to differentiate lie and joke along with cluster 1 and 2 abilities.

These clusters corresponded to severe, mild, and moderate signs of ASD, respectively. Children belonging to cluster 1 attended autism-specific school, cluster 2 attended both autism-specific and special school, and cluster 3 children attended a special school and mainstream schools for better social emotional understanding. ${ }^{97}$

From the collective perceptive on theories of emotion and theory of mind, it can be inferred that individual with ASD finds it hard to perform the emotional reciprocity and the general theories on emotion may be adequate for the neurotypical individuals. Besides the fact that individual with ASD not to be compared with a neurotypical individual for emotional reciprocity, notable research studies show the significant improvement in the individual with ASD in their emotional state through focused interventions.

\section{Assessment and Autism}

Researchers have studied the prevalence of autism and discussed the difficulties in getting its estimates. ${ }^{98-100}$ Among them, the lack of uniformity in the application of fully validated and translated ASD diagnostic tools takes priority. ${ }^{101,102}$ There are numerous measures related to autism, developed in various countries that are being used for screening and diagnosis, but their functionality and reliability vary according to different research studies and some have remained questionable. Some of the widely used ASD assessments include Autism Diagnostic Observation Schedule (ADOS), Autism Diagnostic Interview-Revised 
(ADI-R), Childhood Autism Rating Scale (CARS), Gilliam Autism Rating Scale (GARS), and Social Communication Questionnaire (SCQ). Better suited for the Indian population are the INCLEN Diagnostic Tool for Autism Spectrum Disorder (INDT-ASD) and Indian Scale for Assessment of Autism (ISAA).

To give an overview of the few widely used scales on autism assessment and the importance of assessing comorbid difficulties especially social-emotional reciprocity, a few measures are briefed in the following text.

The ADOS by Lord et al ${ }^{103}$ and the ADI-R by Le Couteur et $\mathrm{al}^{104}$ have long been considered as the "gold standard" in diagnostic evaluations for autism, particularly when combined with clinical judgment. ${ }^{103}$

ADOS-2 $2^{105}$ is a structured, standardized assessment of communication, social interaction, and play or imaginative use of materials for individuals who have been referred because of possible autism or autistic spectrum disorders. Communication observations include vocalizations, using words and phrases; it also shows whether the individual uses functional, social, and gestural communication. Reciprocal social interaction measures elements like eye gaze and facial expression (response to name call, presence of social smile). Stereotyped behaviors and restricted interests assess sensory processing issues and interests such as hand flapping and other repetitive movements. The imaginative play describes the individual's ability to use symbolic imitation (pretend play). The ADOS-2 includes five modules-toddler module (12-30 months); module-1 (above 31 months, do not consistently use phrase speech), module-2 (any age who use phrase speech but not verbally fluent), module-3 (verbally fluent children and young adolescents), and module-4 (verbally fluent older adolescents and adults). Based on the expressive language level and chronological age, a module is chosen to be administered. ${ }^{103}$

The ADI-R is another widely used semistructured diagnostic interview to assess behaviors related to autism or autistic spectrum disorders. The ADI-R is a shorter version of the original interview ${ }^{106}$ and is designed for adults and children with a chronological age of at least 2 years old and a mental age above 2 years. Composed of 93 questions, the ADI-R focuses on three functional domains -language/communication (speech development, appropriate word use, ability to sustain conversation); reciprocal social interactions (interacting with others, showing or interpreting emotions); and restricted, repetitive, and stereotyped behaviors and interests (fixation on unusual items, irrational hand flapping or repeating phrases out of context). It also contains questions about the child's early development such as his/her family background, developmental milestones, and other clinically relevant behaviors such as aggression, self-injury, and possible epileptic features. ${ }^{104}$

An extensively used rating scale for the detection and diagnosis of autism is the CARS by Schopler et al. ${ }^{107}$ The most recent version is the second edition-CARS-2, which consists of 14 domains that assess behaviors associated with autism and a 15th domain that rates general impressions of autism. It consists of three forms: Standard Version Rating
Booklet (CARS2-ST) for use with individuals younger than 6 years of age and those with communication difficulties or below-average estimated IQs; High-Functioning Version Rating Booklet (CARS2-HF) for assessing individuals older than 6 years of age and with IQ scores above 80 and Questionnaire for Parents or Caregivers (CARS2-QPC) that gathers information of the individual's early development; social, emotional, and communication skills; repetitive behaviors; play and routines; and unusual sensory interests from the parents or caretakers. The 14 categories evaluated in CARS- 2 include relating to people, imitation, emotional response, body use, object use, adaptation to change, visual response, listening response, taste, smell, and touch response and use, fear, or nervousness, verbal communication, nonverbal communication, activity level, and consistency of intellectual response. ${ }^{108}$

The Gilliam Autism Rating Scale, currently at its third edition (GARS-3) $)^{109}$ is another screening tool for ASD intended for use in individuals between ages 3 and 22. It assists teachers, parents, and clinicians in identifying autism in individuals and estimating its severity. The instrument consists of 58 items describing the characteristic behaviors of persons with autism grouped into six subscales of restrictive/repetitive behaviors, social interaction, social communication, emotional responses, cognitive style, and maladaptive speech. ${ }^{109}$

The SCQ is another well-known screening instrument designed to evaluate communication skills and social functioning in children suspected of having ASD. The questions on the SCQ were developed based on items from the Autism Diagnostic Interview $^{106}$ and suitable for individuals over 4 years of age and have a mental age of 2 years and above. The questionnaire consists of two forms-lifetime and current-each composed of just 40 yes-or-no questions that can be given directly to the parent, who can answer the questions without supervision. While the lifetime form focuses on the child's entire developmental history, the current form looks at the child's behavior over the most recent 3-month period. The former identifies if the individual has to be referred for a more complete evaluation and the latter produces results that can be helpful in treatment planning, educational intervention, and measurement of change over time. ${ }^{110}$

The INDT-ASD is used as a screening tool to identify the presence of ASD and further understand where the individual falls in the spectrum. It is administrable on children from age 2 to 9 years; this tool is based on both history from primary caregivers and direct observation of the child. It has two sections: Section A has 29 symptoms/items and Section $B$ contains 12 questions corresponding to $B$ and $C$ domains of DSM-IV-TR (social interaction, communication and restricted interests), time of onset, duration of symptoms, score, and diagnostic algorithm. ${ }^{111}$

The ISAA used for diagnosing and measuring the severity of autism. It enables clinicians to quantify the severity of autistic symptoms so as to enable measurement of associated disability. The ISAA was developed based on CARS and has 40 items divided under six domains-social relationship and reciprocity; emotional responsiveness; speech, language and communication; behavior patterns; sensory aspects 
and cognitive component. The result from the scale will indicate the mild, moderate, and severe functioning level of individual with ASD. ${ }^{12}$

\section{Discussion}

Over a decade of medical research, more than hundreds of genes had been identified and found to contribute to the deficits in social, behavior, and cognitive function of the individual. In autism, COMT, SLC6A4, OXTR, FKBP5, and PACAP genes are found to have a connection with emotional deficiency. From the collective literature, this narrative review empathizes the incongruence of the theories of emotion and theory of mind in relation with condition of ASD and some of the gold standard autism assessment tools that can be used clinically for the therapeutic intervention evaluation and certification of the individual with ASD.

\section{Implication and Future Direction for Research}

The cognitive and behavioral aspects of treating children with ASD by various intervention techniques provided significant improvement in their normal functioning. The advanced research performed in the medical field on autism contributed a lot in terms of accurate diagnosis and to find the level of functioning such as mild, moderate, or severe. All of the above yielded theoretical and empirical evidence for the effort performed over the decade by numerous mental health professionals, but, still, it does not provide the comprehensive treatment outcome because of the minimal focuses on emotional reciprocity. Children with autism frequently find it hard to perceive and control emotions. Their ability in the area of emotional reciprocity can be improved, which can assist them with comprehension and react in an appropriate way to different people. As of now, no treatment has been appeared to cure ASD, yet a few interventions have been developed and implemented for the benefit of children with ASD. These interventions may reduce symptoms, improve cognitive ability and daily living functioning, and boost the capacity of the children to work and participate in the social gathering. Research shows that early intervention treatment can altogether improve a child's development, which we theoretically evaluated in the most important domain on emotion. Enhancing emotion among individuals with autism is time-consuming, but it is effective in decreasing various issues, such as behavior problems and aggression, psychiatric symptoms like anxiety and depression and it also decreases functional impairments across settings like community, work, school. To decrease such issues, individuals with ASD should be able to regulate their emotions. This occurs only when the individual can recognize and understand their emotions. Hence, this review will theoretically support and influence the future studies related to emotional reciprocity and regulation for the better therapeutic plan.

\section{Clinical and Research Implication}

Autism research is vital for individual currently diagnosed and as well as for those with clinical symptoms of neurodevelopmental condition. The in-depth critical literature reviews such as the connection between autism and emotion will shed light on understanding emotional reciprocity level, identifying emotional problems, developing effective intervention strategies for those with the condition of ASD. Most of the theories are expected to be proved in the form of experiment and need further validation for scientific justification. The arguments and scientific evidence of emotional related theories that are supporting and nonsupporting the condition of autism are discussed here for the further clinical understanding. The behavioral therapists and clinical psychologists who work and develop appropriate intervention technique can consider these aspects on emotion and incorporate appropriate methods to address the emotional need of people with autism.

\section{Conclusion}

This comprehensive review article emphasizes the factors of the genetic mechanism that influence autistic features, also irreconcilable of theories of emotion and theory of mind in relation to individual with ASD. The broadly used autism assessment scales and their domains are elaborated. Most importantly, the future need for the research in emotional area on autism is briefly explained.

Conflict of Interest

None declared.

\section{References}

1 World Health Organization. International classification of diseases for mortality and morbidity statistics, $11^{\text {th }}$ Revi. Accessed August 10, 202 at: https://icd.who.int/browse11/l-m/en

2 Kopetz PB, Endowed ED. Autism worldwide: prevalence, perceptions, acceptance, action. J Soc Sci 2012;8:196-201

3 Matson JL, Worley JA, Fodstad JC, et al. A multinational study examining the cross cultural differences in reported symptoms of autism spectrum disorders: Israel, South Korea, the United Kingdom, and the United States of America. Res in Aut Spec Dis 2011;5:1598-1604

4 Rice CE, Rosanoff M, Dawson G, et al. Evaluating changes in the prevalence of the autism spectrum disorders. Public Health Rev 2012;34(02):1-22

5 Christensen DL, Baio J, Van Naarden Braun K, et al; Centers for Disease Control and Prevention (CDC) Centers for Disease Control and Prevention (CDC). Prevalence and characteristics of autism spectrum disorder among children aged 8 years-autism and developmental disabilities monitoring network, 11 Sites, United States, 2012. MMWR Surveill Summ 2016;65(03):1-23

6 Mannion A, Leader G. Comorbidity in autism spectrum disorder: a literature review. Res in Aut Spec Dis 2013;7:1595-1616

7 Doshi-Velez F, Ge Y, Kohane I. Comorbidity clusters in autism spectrum disorders: an electronic health record time-series analysis. Pediatrics 2014;133(01):e54-e63

8 Romero M, Aguilar JM, Del-Rey-Mejías Á, et al. Psychiatric comorbidities in autism spectrum disorder: A comparative study between DSM-IV-TR and DSM-5 diagnosis. Int J Clin Health Psychol 2016;16(03):266-275

9 Corsello CM. Early intervention in autism. Infants Young Child 2005;18:74-85

10 Kasari C, Patterson S. Interventions addressing social impairment in autism. Curr Psychiatry Rep 2012;14(06):713-725 
11 DeFilippis M, Wagner KD. Treatment of autism spectrum disorder in children and adolescents. Psychopharmacol Bull 2016;46 (02):18-41

12 Pasco G. The value of early intervention for children with autism. Pediatr and Chil Heal 2018;28:364-367

13 Sagayaraj K, Gopal CNR, Karthikeyan S. The efficacy of technology and non-technology based intervention for children with autism spectrum disorder: a meta-analysis. Inter J Inno Sci and Res Tech 2020;5:863-868

14 Aman MG, Novotny S, Samango-Sprouse C, et al. Outcome measures for clinical drug trials in autism. CNS Spectr 2004;9 (01):36-47

15 Posey DJ, Stigler KA, Erickson CA, McDougle CJ. Antipsychotics in the treatment of autism. J Clin Invest 2008;118(01):6-14

16 Hampson DR, Gholizadeh S, Pacey LKK. Pathways to drug development for autism spectrum disorders. Clin Pharmacol Ther 2012;91(02):189-200

17 Ghosh A, Michalon A, Lindemann L, Fontoura P, Santarelli L. Drug discovery for autism spectrum disorder: challenges and opportunities. Nat Rev Drug Discov 2013;12(10):777-790

18 World Health Organization. News room, Fact sheet, Detail Autism Spectrum Disorder. 2021 Jun 1.(Cited 2021 Jul 1); Accessed August 09, 2021 from https://www.who.int/news-room/factsheets/detail/autism-spectrum-disorders

19 Sun X, Allison C. A review of the prevalence of autism spectrum disorder in Asia. Res Autism Spectr Disord 2010;4 (02):156-167

20 Hossain MD, Ahmed HU, Jalal Uddin MM, et al. Autism spectrum disorders (ASD) in South Asia: a systematic review. BMC Psychiatry $2017 ; 17(01): 281$

21 Arora NK, Nair MKC, Gulati S, et al. Neurodevelopmental disorders in children aged 2-9 years: population-based burden estimates across five regions in India. PLoS Med 2018;15(07): e1002615

22 Rylaarsdam L, Guemez-Gamboa A. Genetic causes and modifiers of autism spectrum disorder. Front Cell Neurosci 2019;13:385

23 Hori K, Nagai T, Shan W, et al. Heterozygous disruption of autism susceptibility candidate 2 causes impaired emotional control and cognitive memory. PLoS One 2015;10(12):e0145979

24 Bevilacqua L, Goldman D. Genetics of emotion. Trends Cogn Sci 2011;15(09):401-408

25 Yavich L, Forsberg MM, Karayiorgou M, Gogos JA, Männistö PT. Site-specific role of catechol-O-methyltransferase in dopamine overflow within prefrontal cortex and dorsal striatum. J Neurosci 2007;27(38):10196-10209

26 Scanlon PD, Raymond FA, Weinshilboum RM. Catechol-O-methyltransferase: thermolabile enzyme in erythrocytes of subjects homozygous for allele for low activity. Science 1979;203 (4375):63-65

27 Enoch MA, Xu K, Ferro E, Harris CR, Goldman D. Genetic origins of anxiety in women: a role for a functional catechol-0-methyltransferase polymorphism. Psychiatr Genet 2003;13(01):33-41

28 Dapretto M, Davies MS, Pfeifer JH, et al. Understanding emotions in others: mirror neuron dysfunction in children with autism spectrum disorders. Nat Neurosci 2006;9(01):28-30

29 Pessoa L. Emergent processes in cognitive-emotional interactions. Dialogues Clin Neurosci 2010;12(04):433-448

30 Ursini G, Bollati V, Fazio L, et al. Stress-related methylation of the catechol-O-methyltransferase Val 158 allele predicts human prefrontal cognition and activity. J Neurosci 2011;31(18): 6692-6698

31 Meyer-Lindenberg A, Weinberger DR. Intermediate phenotypes and genetic mechanisms of psychiatric disorders. Nat Rev Neurosci 2006;7(10):818-827

32 Rzhetsky A, Wajngurt D, Park N, Zheng T. Probing genetic overlap among complex human phenotypes. Proc Natl Acad Sci U S A 2007;104(28):11694-11699
33 Lesch KP, Bengel D, Heils A, et al. Association of anxiety-related traits with a polymorphism in the serotonin transporter gene regulatory region. Science 1996;274(5292):1527-1531

34 Piven J, Chase GA, Landa R, et al. Psychiatric disorders in the parents of autistic individuals. J Am Acad Child Adolesc Psychiatry 1991;30(03):471-478

35 Tordjman S, Anderson GM, McBride PA, et al. Plasma betaendorphin, adrenocorticotropin hormone, and cortisol in autism. J Child Psychol Psychiatry 1997;38(06):705-715

$36 \mathrm{Hu}$ XZ, Lipsky RH, Zhu G, et al. Serotonin transporter promoter gain-of-function genotypes are linked to obsessive-compulsive disorder. Am J Hum Genet 2006;78(05):815-826

37 Hariri AR, Mattay VS, Tessitore A, et al. Serotonin transporter genetic variation and the response of the human amygdala. Science 2002;297(5580):400-403

38 Heinz A, Braus DF, Smolka MN, et al. Amygdala-prefrontal coupling depends on a genetic variation of the serotonin transporter. Nat Neurosci 2005;8(01):20-21

39 Pezawas L, Meyer-Lindenberg A, Drabant EM, et al. 5-HTTLPR polymorphism impacts human cingulate-amygdala interactions: a genetic susceptibility mechanism for depression. Nat Neurosci 2005;8(06):828-834

40 Caspi A, Sugden K, Moffitt TE, et al. Influence of life stress on depression: moderation by a polymorphism in the 5-HTT gene. Science 2003;301(5631):386-389

41 Lonsdorf TB, Weike AI, Nikamo P, Schalling M, Hamm AO, Ohman A. Genetic gating of human fear learning and extinction: possible implications for gene-environment interaction in anxiety disorder. Psychol Sci 2009;20(02):198-206

42 Lee HJ, Macbeth AH, Pagani JH, Young WS III. Oxytocin: the great facilitator of life. Prog Neurobiol 2009;88(02):127-151

43 Kirsch P. Oxytocin in the socioemotional brain: implications for psychiatric disorders. Dialogues Clin Neurosci 2015;17(04): 463-476

44 Windle RJ, Shanks N, Lightman SL, Ingram CD. Central oxytocin administration reduces stress-induced corticosterone release and anxiety behavior in rats. Endocrinology 1997;138(07): 2829-2834

45 Kirsch P, Esslinger C, Chen Q et al. Oxytocin modulates neural circuitry for social cognition and fear in humans. J Neurosci 2005;25(49):11489-11493

46 Koch SB, van Zuiden M, Nawijn L, Frijling JL, Veltman DJ, Olff M. Intranasal oxytocin normalizes amygdala functional connectivity in posttraumatic stress disorder. Neuropsychopharmacology 2016;41(08):2041-2051

47 Auyeung B, Lombardo MV, Heinrichs M, et al. Oxytocin increases eye contact during a real-time, naturalistic social interaction in males with and without autism. Transl Psychiatry 2015;5:e507

48 Lucht MJ, Barnow S, Sonnenfeld C, et al. Associations between the oxytocin receptor gene (OXTR) and affect, loneliness and intelligence in normal subjects. Prog Neuropsychopharmacol Biol Psychiatry 2009;33(05):860-866

49 Yamasue H, Domes G. Oxytocin and autism spectrum disorders. Curr Top Behav Neurosci 2018;35:449-465

50 LoParo D, Waldman ID. The oxytocin receptor gene (OXTR) is associated with autism spectrum disorder: a meta-analysis. Mol Psychiatry 2015;20(05):640-646

51 Yamasue H. Function and structure in social brain regions can link oxytocin-receptor genes with autistic social behavior. Brain Dev 2013;35(02):111-118

52 Ahima RS, Harlan RE. Charting of type II glucocorticoid receptorlike immunoreactivity in the rat central nervous system. Neuroscience 1990;39(03):579-604

53 Kovács KJ, Földes A, Sawchenko PE. Glucocorticoid negative feedback selectively targets vasopressin transcription in parvocellular neurosecretory neurons. J Neurosci 2000;20(10): 3843-3852 
54 Criado-Marrero M, Rein T, Binder EB, Porter JT, Koren J III, Blair LJ. Hsp90 and FKBP51: complex regulators of psychiatric diseases. Philos Trans R Soc Lond B Biol Sci 2018;373(1738):20160532

55 Binder EB, Salyakina D, Lichtner P, et al. Polymorphisms in FKBP5 are associated with increased recurrence of depressive episodes and rapid response to antidepressant treatment. Nat Genet 2004;36(12):1319-1325

56 Willour VL, Chen H, Toolan J, et al; Bipolar Disorder Phenome Group NIMH Genetics Initiative Bipolar Disorder Consortium. Family-based association of FKBP5 in bipolar disorder. Mol Psychiatry 2009;14(03):261-268

57 Ising M, Depping AM, Siebertz A, et al. Polymorphisms in the FKBP5 gene region modulate recovery from psychosocial stress in healthy controls. Eur J Neurosci 2008;28(02):389-398

58 Ressler KJ, Mercer KB, Bradley B, et al. Post-traumatic stress disorder is associated with PACAP and the PAC1 receptor. Nature 2011;470(7335):492-497

59 Falluel-Morel A, Tascau LI, Sokolowski K, Brabet P, DiCicco-Bloom E. Granule cell survival is deficient in PAC1-/- mutant cerebellum. J Mol Neurosci 2008;36(1-3):38-44

60 Ghzili H, Grumolato L, Thouënnon E, et al. Role of PACAP in the physiology and pathology of the sympathoadrenal system. Front Neuroendocrinol 2008;29(01):128-141

61 Harmar T, Lutz E. Multiple receptors for PACAP and VIP. Trends Pharmacol Sci 1994;15(04):97-99

62 Hashimoto H, Shintani N, Baba A. New insights into the central PACAPergic system from the phenotypes in PACAP- and PACAP receptor-knockout mice. Ann N Y Acad Sci 2006;1070:75-89

63 Mounien L, Do Rego JC, Bizet P, et al. Pituitary adenylate cyclaseactivating polypeptide inhibits food intake in mice through activation of the hypothalamic melanocortin system. Neuropsychopharmacology 2009;34(02):424-435

64 Stroth N, Holighaus Y, Ait-Ali D, Eiden LE. PACAP: a master regulator of neuroendocrine stress circuits and the cellular stress response. Ann N Y Acad Sci 2011;1220:49-59

65 Dias BG, Ressler KJ. PACAP and the PAC1 receptor in posttraumatic stress disorder. Neuropsychopharmacology 2013;38 (01):245-246

66 Mercer KB, Dias B, Shafer D, et al. Functional evaluation of a PTSD-associated genetic variant: estradiol regulation and ADCYAP1R1. Transl Psychiatry 2016;6(12):e978

67 Davis M. The role of the amygdala in fear and anxiety. Annu Rev Neurosci 1992;15:353-375

68 Diener SJ, Nees F, Wessa M, et al. Reduced amygdala responsivity during conditioning to trauma-related stimuli in posttraumatic stress disorder. Psychophysiology 2016;53(10):1460-1471

69 Giustino TF, Maren S. The role of the medial prefrontal cortex in the conditioning and extinction of fear. Front Behav Neurosci 2015;9:298

70 Shin LM, Rauch SL, Pitman RK. Amygdala, medial prefrontal cortex, and hippocampal function in PTSD. Ann N Y Acad Sci 2006;1071:67-79

71 Goodrich M, Armour AC, Panchapakesan K, et al. PAC1R genotype to phenotype correlations in autism spectrum disorder. Autism Res 2019;12(02):200-211

72 Baron-Cohen S. Do people with autism understand what causes emotion? Child Dev 1991;62(02):385-395

73 Losh M, Capps L. Understanding of emotional experience in autism: insights from the personal accounts of high-functioning children with autism. Dev Psychol 2006;42(05):809-818

74 Gaigg SB. The interplay between emotion and cognition in autism spectrum disorder: implications for developmental theory. Front Integr Nuerosci 2012;6:113

75 Fitzpatrick P, Frazier JA, Cochran D, Mitchell T, Coleman C, Schmidt RC. Relationship between theory of mind, emotion recognition, and social synchrony in adolescents with and without autism. Front Psychol 2018;9:1337

76 James W. What is an emotion? Mind 1884;9:188-205
77 Lange CG. The Mechanism of the Emotions. Boston: Houghton Mifflin; 1912:672-684

78 Clarke C. Autism spectrum disorder and amplified pain. Case Reports in Psyc 2015;2015:930874

$79 \mathrm{Gu}$ X, Zhou TJ, Anagnostou E, et al. Heightened brain response to pain anticipation in high-functioning adults with autism spectrum disorder. Eur J Neurosci 2018;47(06):592-601

80 Vaughan S, McGlone F, Poole H, Moore DJ. A quantitative sensory testing approach to pain in autism spectrum disorders. J Autism Dev Disord 2020;50(05):1607-1620

81 Friedman BH. Feelings and the body: the Jamesian perspective on autonomic specificity of emotion. Biol Psychol 2010;84(03): 383-393

82 Newman EB, Perkins FT, Wheeler RH. Cannon's theory of emotion: a critique. Psychol Rev 1930;37:305-326

83 Poquérusse J, Pastore L, Dellantonio S, Esposito G. Alexithymia and autism spectrum disorder: a complex relationship. Front Psychol 2018;9:1196

84 Sifneos PE. The prevalence of 'alexithymic' characteristics in psychosomatic patients. Psychother Psychosom 1973;22(02): 255-262

85 Hadjikhani N, Zürcher NR, Rogier O, et al. Emotional contagion for pain is intact in autism spectrum disorders. Transl Psychiatry 2014;4:e343

86 Meng J, Li Z, Shen L. Responses to others' pain in adults with autistic traits: The influence of gender and stimuli modality. PLoS One 2017;12(03):e0174109

87 Schachter S, Singer JE. Cognitive, social, and physiological determinants of emotional state. Psychol Rev 1962;69:379-399

88 Tager-Flusberg $\mathrm{H}$. A psychological approach to understanding the social and language impairments in autism. Int Rev Psychiatry 1999;11(04):325-334

89 Macari S, DiNicola L, Kane-Grade F, et al. Emotional expressivity in toddlers with autism spectrum disorder. J Am Acad Child Adolesc Psychiatry 2018;57(11):828-836.e2

90 Lazarus RS. Emotion and Adaptation. New York: Oxford University Press; 1991

91 Green L, Fein D, Joy S, et al. Cognitive functioning in autism. In: Schopler E, Mesibov GB, eds. Learning and Cognition in Autism. Current Issues in Autism Boston: Springer; 1995:13-31

92 Barrett LF, Mesquita B, Ochsner KN, Gross JJ. The experience of emotion. Annu Rev Psychol 2007;58:373-403

93 Darwin CR. The Expression of the Emotions in Man and Animals. London: John Murray; 1872

94 Perkins T, Stokes M, McGillivray J, Bittar R. Mirror neuron dysfunction in autism spectrum disorders. J Clin Neurosci 2010;17(10):1239-1243

95 Premack D, Woodruff G. Does the chimpanzee have a theory of mind? Behav Brain Sci 1978;1:515-526

96 Baron-Cohen S. The theory of mind deficit in autism: how specific is it? British J Dev Psy 1991;9:301-314

97 Baron-Cohen S, Leslie AM, Frith U. Does the autistic child have a "theory of mind"? Cognition 1985;21(01):37-46

98 Tine M, Lucariello J. Unique theory of mind differentiation in children with autism and Asperger syndrome. Autism Res Treat 2012;2012:505393

99 Hoogenhout M, Malcolm-Smith S. Theory of mind predicts severity level in autism. Autism 2017;21(02):242-252

100 Chauhan A, Sahu JK, Jaiswal N, et al. Prevalence of autism spectrum disorder in Indian children: a systematic review and meta-analysis. Neurol India 2019;67(01):100-104

101 Malhotra S, Vikas A. Pervasive developmental disorders: Indian scene. J Indian Association of Child Adolescent Mental Health 2005;1:5

102 Rudra A, Banerjee S, Singhal N, Barua M, Mukerji S, Chakrabarti B. Translation and usability of autism screening and diagnostic tools for autism spectrum conditions in India. Autism Res 2014;7 (05):598-607 
103 Lord C, Rutter M, Pamela C, et al. ADOS: Autism Diagnostic Observation Schedule. Boston, MA: Hogrefe; 2008

104 Rutter M, Le Couteur A, Lord C. ADI-R: Autism Diagnostic Interview-Revised (ADI-R). Los Angeles, CA: Western Psychological Services; 2003

105 Lord C, Rutter M, DiLavore P, et al. Autism Diagnostic Observation Schedule. 2nd edition (ADOS-2) Los Angeles, CA: Western Psychological Corporation; 2012

106 Le Couteur A, Rutter M, Lord C, et al. Autism diagnostic interview: a standardized investigator-based instrument. J Autism Dev Disord 1989;19(03):363-387

107 Schopler E, Reichler RJ, DeVellis RF, Daly K. Toward objective classification of childhood autism: Childhood Autism Rating Scale (CARS). J Autism Dev Disord 1980;10(01):91-103

108 Schopler E, Van Bourgondien ME, Wellman GJ, et al. CARS-2: Childhood Autism Rating Scale. Second Edition Los Angeles, CA: West Psy Ser; 2010

109 Gilliam JE. GARS-3: Gilliam Autism Rating Scale. Third edition Austin, TX: PRO-ED; 2014

110 Rutter M, Bailry A, Lord C. The Social Communication Questionnaire. Los Angeles: West Psy Ser; 2003
111 Juneja M, Mishra D, Russell PS, et al; INCLEN Study Group. INCLEN Diagnostic Tool for Autism Spectrum Disorder (INDTASD): development and validation. Indian Pediatr 2014;51(05): 359-365

112 National Institute for Mentally Handicapped, Ministry of Social Justice and Empowerment, Department of Empowerment of Persons with Disabilities. (Divyangjan) Government of India. Indian Scale for Assessment of Autism (ISAA) Test ManualNew Delhi2009

113 de Bildt A, Sytema S, Ketelaars C, et al. Interrelationship between Autism Diagnostic Observation Schedule-Generic (ADOS-G), Autism Diagnostic Interview-Revised (ADI-R), and the Diagnostic and Statistical Manual of Mental Disorders (DSM-IV-TR) classification in children and adolescents with mental retardation. J Autism Dev Disord 2004;34(02):129-137

114 Wong CM, Singhal S. INDT-ASD: an autism diagnostic tool for Indian children. Developmental pediatrician's perspective. Indian Pediatr 2014;51(05):355-356

115 Raina SK, Kashyap V, Bhardwaj AK, Kumar D, Chander V. Prevalence of autism spectrum disorders among children (1-10 years of age) - findings of a mid-term report from Northwest India. J Postgrad Med 2015;61(04):243-246 